\title{
Kenya leads the way in environmental planning
}

THE government of Kenya has started a systematic across-the-board environmental assessment of its entire development programme--the first national exercise of its kind in the Third World. Officials at the United Nations Environment Programme (UNEP) and the United Nations Development Programme (UNDP), both of which are assisting Kenya in executing the project, are enthusiastic about this project.

Its success should help UNDP to promote similar environmental assessment projects in other developing countries, where many policy makers continue to harbour the same mistrust towards the environmental debate that they displayed at the Stockholm conference in 1972. While many argue that environmental considerations are a luxury for Third World development planners, there are others who see in environmentalism a philosophy designed to retard the economic development of the Third World, particularly its industrial development.

The Kenyans are quite aware that there can be strong conflicts between environment and development. They are therefore looking for only limited but quite realistic results from their exercise. At the least, it should help to reduce those innumerable environmental problems that are often created because of simple oversights at the planning stage.

Kenya's Tana River development scheme, for instance, will create one of the biggest man-made lakes in Africa. The spread of irrigation carries the threat of schistosomiasis. Between disease and agricultural prosperity Kenya, like any other Third World

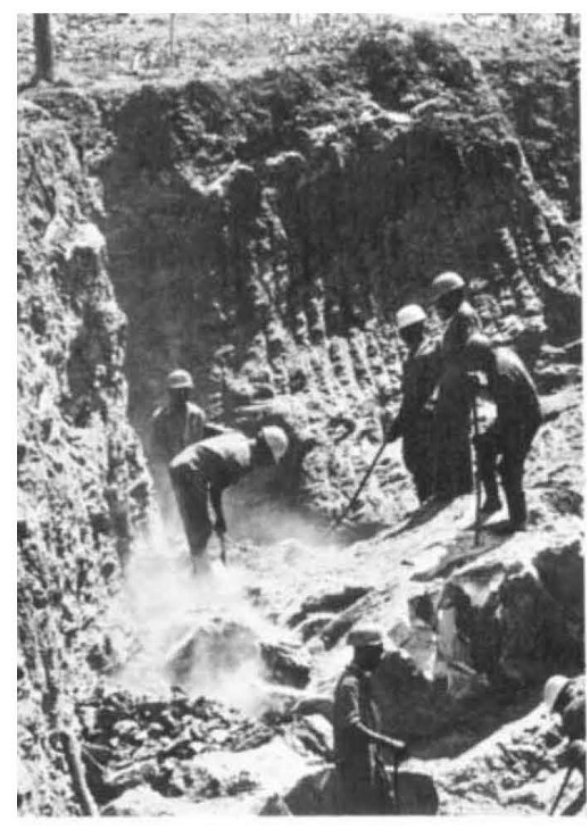

country, would obviously choose the latter. However, an advance environmental assessment exercise would help to promote possible control measures right from the beginning. It would also remind project authorities that the labour force building the dam has to be provided with energy. Otherwise, merely because of this oversight, forests could get depleted, and the resulting soil erosion could lead to rapid silting of the new reservoir.

Environmentally bad siting of projects, like a chemical plant near a bird sanctuary, can be prevented quite easily with the help of such exercises. "To delay the starting of a paper mill after it has been built, neither helps the country nor the firm setting it up", explains George Muhoho, until recently head of Kenya's National Environment Secretariat (NES), the Kenyan agency co-ordinating the environment-development project.

In the past, the NES has conducted several studies on various individual projects and influenced government decisions. But the current exercise now provides it with a rare opportunity to develop a comprehensive and long-term approach to environmental planning in the country.

The final recommendations of the project may well strongly favour a high rate of industrial growth. The most pressing environmental issues in Kenya are those related to land-use. South of the Sahara, Kenya has the highest population growth rate. Kenya's population is expected to double within 20 years. At the moment, nearly $90 \%$ of Kenya's population lives in the rural areas earning its livelihood predominantly from agriculture. Unless a rapid transformation takes place in the occupational structure of the country and more people find jobs in industry, the pressure on the land could become too intense.

As increasingly marginal land is brought under cultivation, deforestation and desertification will increase. Encroachment on game parks could seriously affect wildlife conservation. By contrast, Kenya could simply forget about air pollution control until it has reached a far higher level of industrial

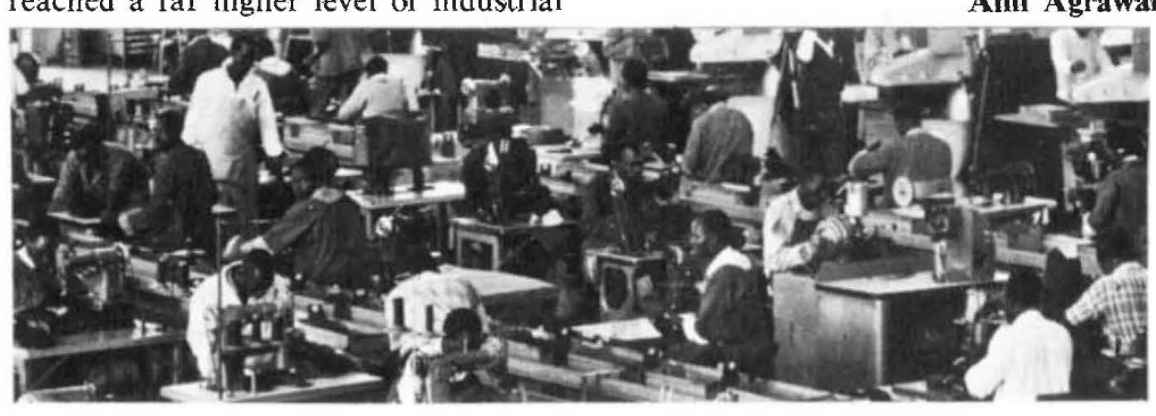

The pressure on land : environmental oversights can limit growth

development. A comprehensive environmental planning exercise could thus identify urgent development priorities and critical environmental issues as well.

An important aspect of the project is that it relies largely on local Kenyan expertise. The temptation to invite a UN mission consisting of Western experts to prepare a report on environmental problems was studiously avoided. Such an approach would have robbed the Kenyans of a chance to assess by themselves the environmental effects of what they were doing, and thus develop their own perspective on environment and development related issues. Moreover, even in the West, few people can really stake a claim to be an expert on environment-development planning.

To ensure the involvement of all available local expertise, and popular participation, the project is being executed in three phases. In the first phase, which was completed in August, 1978, five papers were prepared that surveyed major environmental problems in Kenya. These papers were then thrown open for discussions at a weeklong meeting in July, 1978, attended by 11 senior Kenyan officials, including the Minister of Finance and Planning, and several permanent secretaries in the government. This meeting identified existing gaps in knowledge and possible policy alternatives. Finally, a steering committee for the rest of the project was formed consisting of the officials present at the meeting to enlist the active co-operation of all the ministries.

In the second phase, much more specialised studies on specific scientific, technical, legal and sociological issues are being conducted to find answers to the questions raised at the earlier meeting. To do these studies, local expertise will be drawn from wherever available-from official institutions to non-government organisations and universities. Foreign experts will be recruited only for highly technical subjects where no local expertise exists. Finally, in the third phase, to be completed by August, 1979, the final recommendations will be put together.

Anil Agrawal 